\title{
AN EXPERIMENTAL STUDY ON WALL THICKNESS DISTRIBUTION IN THERMOFORMING
}

\author{
Sencer Süreyya Karabeyoglu', Olcay Ekşi', Selçuk Erdoğan²
}

1 Kırklareli University, Engineering Faculty, Mechanical Engineering Department, Kayali Campus, 39100 Kırklareli, Turkey, e-mail: sencerkarabeyoglu@klu.edu.tr, olcayeksi@klu.edu.tr

2 Trakya University, Engineering Faculty, Mechanical Engineering Department, 22100 Edirne, Turkey, e-mail: eselcuk@trakya.edu.tr

Received: 2017.05.15

Accepted: 2017.08.01

Published: 2017.09.03

\begin{abstract}
In this work, Polystyrene (PS) sheets were thermoformed in predetermined conditions. Wall thickness distributions obtained by experimental method in PS thermoformed products. Then the same thickness distributions were predicted by using Geometric Element Analysis (GEA). The thickness results were obtained experimentally, compared to thickness distributions which were predicted by GEA. It has been found that GEA does not precisely reveal thickness distributions.
\end{abstract}

Keywords: Geometric Element Analysis (GEA), wall thickness distribution, polystyrene, thermoforming.

\section{INTRODUCTION}

Manufacturing products from plastic sheets and films has been possible for almost a century. Technological developments in manufacturing industry and polymers have made thermoforming one of the most competitive processes.

Thermoforming is used to produce parts for industries such as food, medical, appliance, signage, and automotive. Thermoforming is used in both high and low volume production operations after sheet-fed and roll-fed thermoforming machines have been used. The major advantages of the process are its low initial tooling costs and low equipment costs when compared to other competitive processes such as extrusion, blow molding, and injection molding [2].

Thermoformed part's quality can be defined by a combination of several parameters. One of these parameters is thickness distribution that affects thermoformed package's gas permeability, which can effect such things as shelf life of the food in the packaging. Thickness distribution has an influence on the package's rigidity too.
Uniform thickness distribution is not possible in thermoforming but more uniform thickness distribution means rigid and stable packages [9, 11]. Thermoforming simulation can be utilized so that a thermoformed product has more uniform thickness distribution. Some engineering packages that are based on Finite Element Analysis, are Ansys Polyflow, Abaqus, T-sim, Pam-form etc. Using simulation software is very effective to estimate how plastic deforms before real thermoforming operations especially in terms of lowering tool costs $[3,5,8,14]$. Heat transfer during heating plastic, applying positive or negative air pressure, including plug assist, deformation behavior of plastic material is possible to simulate by engineering packages mentioned before $[3,8$, 14]. If boundary conditions can be precisely defined, thermoforming simulation may reveal accurate results about thermoformed product. Thermoforming simulation can be used in prediction of thickness distribution in final product too.

Different types of plastics can be formed by thermoforming. Semi-crystalline and amorphous thermoplastics, thermoplastic matrix 


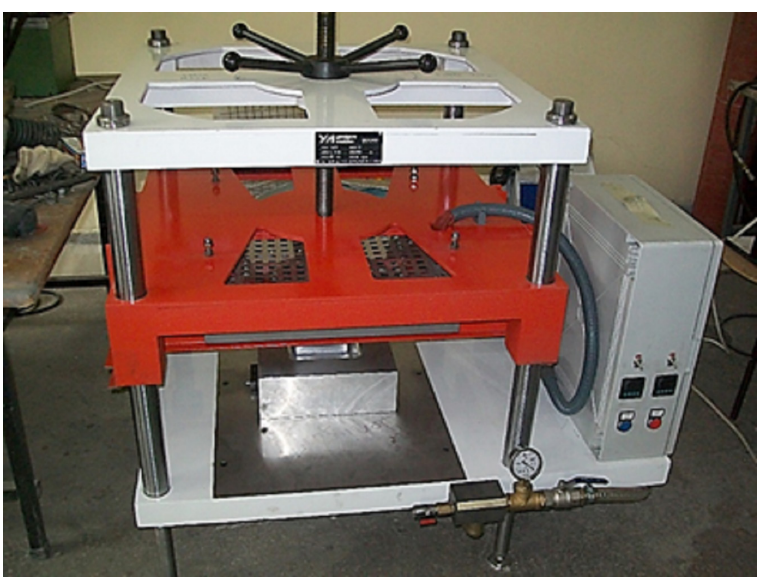

Fig. 1. Thermoforming machine used in this work

composites, nanocomposites even bioplastics [14]. Some additional process parameters affect the wall thickness distribution in thermoforming. Coefficient of friction, shape of clamping rings, use of plug assist, and temperature distribution on the heated sheet, mold design and manufacturing can be counted as part of these parameters $[1,4,6,7,10]$.

In this study, thickness distributions in conical and cylindrical thermoformed products were obtained. In each product thickness, values were predicted by using GEA too. Thickness results obtained by experimental method (using digital caliper, resolution: $0.01 \mathrm{~mm}$ ) compared to thickness profiles predicted by GEA. It can be said that GEA did not predict thickness distributions accurately for conical and cylindrical products. As a result, there is significant difference between the experimental results and GEA predictions. GEA can be used only to show the trend for thickness variation of the product through the mold $[12,13]$.

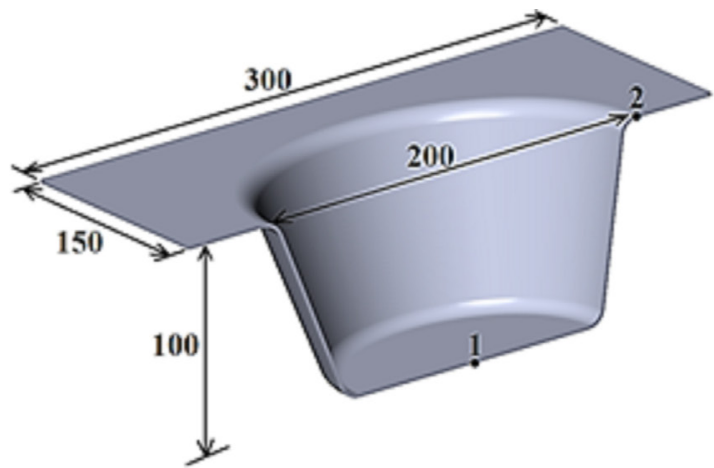

\section{MATERIALS AND METHOD}

In this work, PS sheets extruded from SABIC $($ PS 825E High impact polystyrene for Thermoforming granules were used. These sheets were cut in dimensions of $30 \times 30 \mathrm{~cm}^{2}$. Each sample is $2 \mathrm{~mm}$ thick.. Two different thermoforming molds have been employed in forming operations. These molds have been placed in the Lab-scale thermoforming machine produced by YENIYURT Machine Corp. Lab-scale thermoforming machine was designed and produced only for experimental laboratory applications. Productivity and automation has been neglected because of cost. That thermoforming machine can be called as sheet fed thermoformer. Each sheet sample that is prepared to the desired dimensions is placed on to the mold one at a time by the operator. Then the sheets are heated. After heating, a vacuum is applied. After cooling, the semi-finished product can be released from the mold. One of the differences of this machine is that sheets or films can be formed by using just a vacuum. On the other hand, in the other machines vacuum and positive air pressure may be used together. With lab scale thermoforming machine used in this work, cylindrical and conical female molds were used. In Fig. 1. Lab-scale machine is shown.

Thermoforming machine has four ceramic radiant heater elements that heat $30 \times 30 \mathrm{~cm}^{2}$ surface area. The heaters temperature were adjusted to $350^{\circ} \mathrm{C}$. After an appropriate waiting time for heating, temperatures were measured on the heated sheet by a thermal imaging cam (Testo). Heating temperature was measured approximately as $150^{\circ} \mathrm{C}$. Then the heaters were turned off. Vacuum was applied and the sheet was formed by the aid of a vacuum. Vacuum value was obtained as between $720-730 \mathrm{mmHg}$ from vacuum display. After cooling, the samples were released from the mold.

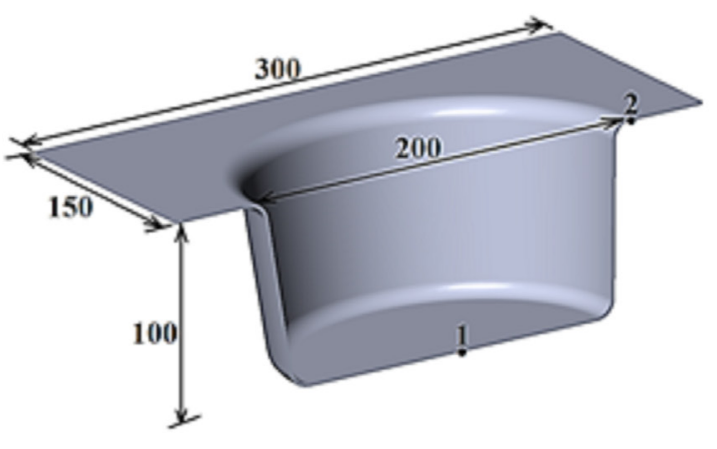

Fig. 2. Dimensions of half conical and cylindrical thermoformed products in $\mathrm{mm}$ 
Quarter sections from vacuum formed samples were cut and taken by machining. Then wall thickness measurements were performed on these quarter samples. Thickness measurements were made with a digital caliper (Mitutoyo, resolution: $0.01 \mathrm{~mm}$ ) on selected profiles. Thickness values were measured on more than 30 points at determined sections. Then thickness distribution results were predicted by GEA. In Fig. 2. cylindrical and conical half samples can be shown clearly.

The wall thickness measurements were repeated on at least three different samples for cylindrical and conical products. Thicknesses were measured along a vertical cut passing through the center of the product from point 1 to point 2. Thicknesses were predicted between the same points by GEA too. These thickness distributions were compared to each other.

\section{RESULTS AND DISCUSSION}

Obtained and predicted thickness distributions for conical and cylindrical products are shown in Fig. 3 and Fig. 4. Thicknesses were measured from point 1 to point 2 at more than 30 points. As understood from Fig. 3. measured thickness distribution on conical product has showed a slightly decreasing trend and then increased to a thickness of $2.21 \mathrm{~mm}$ on the last point (Point 2). Although initial sheet thickness is $2 \mathrm{~mm}$, measured thickness value on Point 2 is greater than $2 \mathrm{~mm}$. It is because of the overlapping and thickness accumulation on the sidewalls. The same phenomenon can be seen in Fig. 4 for the cylindrical product due to the same reasons. Minimum thickness was measured as about 0.4 $\mathrm{mm}$ in conical sample but predicted as $0.704 \mathrm{~mm}$. Although obtained and predicted min. thickness-

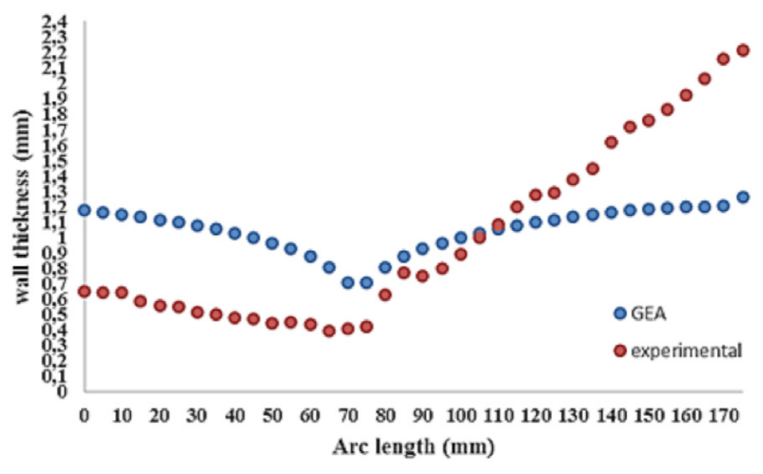

Fig. 3. Comparative thickness distributions obtained on conical sample by GEA and Experimental method

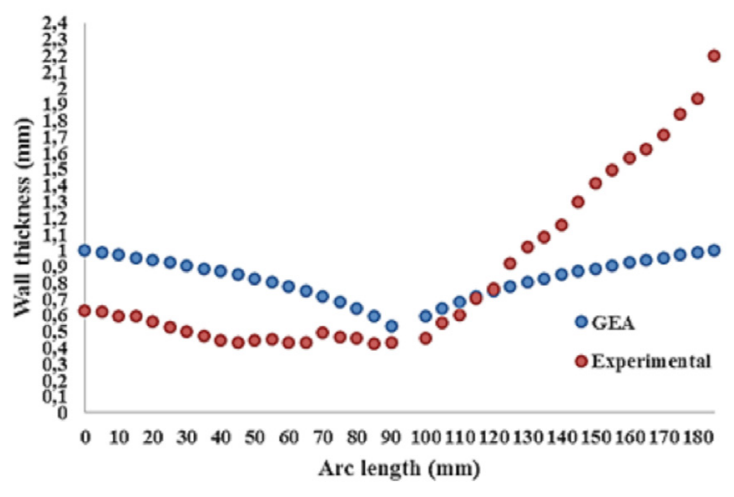

Fig. 4. Comparative thickness distributions obtained on cylindrical sample by GEA and Experimental method

es are different, the points where min. thicknesses were obtained and predicted, are nearly the same. In Fig.4. measured thickness distribution in cylindrical sample showed a constant variation firstly. Then thickness distribution increased to 2.19 $\mathrm{mm}$ on last point(Point 2). Min. thickness was measured as $0.42 \mathrm{~mm}$, calculated as $0.53 \mathrm{~mm}$ by GEA. Predicted thickness distributions may have closer values to measured thickness distributions. But this does not mean that the GEA method is good at estimating the thickness results precisely.

\section{CONCLUSIONS}

In this study, the accuracy of GEA and the correlation between the experimental methods have been investigated. GEA predicted closer thickness results to the measured thicknesses on some points. However, GEA could not predict thickness distributions in cylindrical or conical samples precisely. Results show that GEA can only give an idea of where the min. thickness value occurs. On some points, especially arc length values of $170 \mathrm{~mm}, 175 \mathrm{~mm}$ and $180 \mathrm{~mm}$, thickness values were measured greater than 2 $\mathrm{mm}$, whereas initial sheet thickness was $2 \mathrm{~mm}$. This is because of the overlapping on the radius in cylindrical and conical products. Because of this, thickness accumulation occurs on the radius that is at the top of the sidewalls. Not only minimum thicknesses but also maximum thicknesses were not predicted accurately by GEA. Although GEA is a practical method of producing quick solutions for thermoforming, its usage decreases day by day due to ignoring the required material parameters and not considering required boundary conditions. Instead of the 
GEA method, thermoforming simulation engineering packages that include material models, rheological and mechanical properties of materials and advanced boundary conditions can be employed in complex forming operations.

\section{Acknowledgements}

The Authors would like to thank to Trakya University Engineering Faculty Laboratory for providing to use the lab-scale thermoforming machine.

Additionally, this paper is based on the results of a scientific research project and that research project is supported by Scientific Research Projects Unit of Kurklareli University.

\section{REFERENCES}

1. Chen S.-C., Huang S.-T., Lin M.-C., Chien R.-D.: Study on the thermoforming of PC films used for in-mold decoration. International Communications in Heat and Mass Transfer, 35, 2008, 967-973.

2. Crawford R. J.: Plastics Engineering. ButterworthHeinemann, Oxford 1998.

3. Gupta S., Uday V., Raghuwanshi A. S., Chowkshey S., Das S. N., Suresh S.: Simulation of Blow Molding Using Ansys Polyflow. ICESD 2013, 4th International Conference, APCBEE Procedia, 5, 2013, 468-473.

4. Hauptmann M., Weyhe J., Majschak J.-P.: Optimisation of deep drawn paperboard structures by adaptation ofthe blank holder force trajectory. Journal of Materials Processing Technology, 232, 2016, 142-152.

5. Karamanou M., Warby M.K., Whiteman J.R.: Computational modelling of thermoforming pro- cesses in the case of finite viscoelastic materials. Computer Methods in Applied Mechanics and Engineering, 195, 2006, 5220-5238.

6. McCool R., Martin P.J.: The role of process parameters in determining wall thickness distribution in plug-assisted thermoforming. Polymer Engineering and Science 50, 10, 2010, 1923-1934.

7. Morales R. A., Candal M. V., Santana O. O., Gordillo A., Salazar R.: Effect of the thermoforming process variables on the sheet friction coefficient. Materials \& Design, Materials and Design, 53, 2014, 1097-1103.

8. O'Connor C.P.J., Martina P.J., Sweeney J., Menary G., Caton-Rose P., Spencer P.E.: Simulation of the plug-assisted thermoforming of polypropylene using a large strain thermally coupled constitutive model. Journal of Materials Processing Technology, 213, 2013, 1588- 1600.

9. Osswald T.A.: Polymer Processing Fundamentals. Hanser/Gardner Publications, USA 1998.

10. Tam K.W., Chan K.W.: Thermoforming mould design using a reverse engineering approach. Robotics and Computer-Integrated Manufacturing, 23, 2007, 305-314.

11. Throne J.L., Mooney P.J.: Thermoforming: Growth and Evolution I. Thermoforming Quarterly, USA, 2005.

12. Throne J.L.: Thermoforming, Hanser Publishers, GERMANY, Munich, 1987.

13. Throne J.L.: Technology of Thermoforming, Hanser/Gardner Publications Inc., USA, 1996.

14. Wang P., Hamila N., Boisse P.: Thermoforming simulation of multilayer composites with continuous fibres and thermoplastic matrix. Composites, B, 52, 2013, 127-136. 